\title{
Condensation Chemistry of Circumstellar Grains
}

\author{
Katharina Lodders and Bruce Fegley, Jr. \\ Washington University, Campus Box 1169, St. Louis, MO 63130, USA
}

\begin{abstract}
Thermochemical equilibrium calculations are successful in predicting the mineralogy as well as the major and trace element chemistry of circumstellar grains found in meteorites. The calculations also explain observations of dust close to AGB stars (within 1-3 stellar radii). The trace element chemistry in circumstellar graphite, $\mathrm{SiC}$, and other refractory carbide grains agrees with equilibrium condensation calculations for circumstellar shells of carbon stars. Observed trace element abundance patterns in $\mathrm{N}$ stars are complementary to those found in $\mathrm{SiC}$ grains indicating fractional condensation in circumstellar shells. Condensation temperatures depend upon total pressure, $\mathrm{C} / \mathrm{O}$ ratio, nitrogen abundances, and overall metallicity. Therefore for condensation temperatures to be meaningful, the total pressure and elemental abundances (i.e., $\mathrm{C} / \mathrm{O}$ ratio, metallicity) must be specified.
\end{abstract}

\section{Introduction}

Dust formation in cool circumstellar shells (CS) of AGB stars drives stellar winds and mass-loss leading to enrichment of the interstellar medium with heavy elements. Most of the stardust is composed of the abundant elements such as $\mathrm{O}$, $\mathrm{C}, \mathrm{Mg}, \mathrm{Si}, \mathrm{Fe}, \mathrm{S}, \mathrm{Al}, \mathrm{Ca}$, and $\mathrm{Ti}$. Thermochemical equilibrium calculations have long been successful in modeling the gas chemistry in giant stars (Tsuji 1973) and they are successful as well in predicting the observed types and the trace element chemistry of dust. Many topics discussed in this review have already been described in detail by Lodders \& Fegley (1997a) and this review focuses on the following questions:

1. What types of dust are expected to form in CS of M, S, and C stars? What types of dust are known from astronomical observations and studies of circumstellar dust in meteorites?

2. What is the condensation sequence? How is the condensation sequence influenced by the $\mathrm{C} / \mathrm{O}$ ratio and the nitrogen abundance?

3. At which distance from the star do condensates form? What is the influence of stellar variability?

4. What can be learned about elemental fractionation processes from trace element abundances in stellar atmospheres and circumstellar SiC grains?

5. What future observational and laboratory work is indicated? 


\section{Applicability of thermochemical equilibrium calculations to cir- cumstellar shells}

Several different arguments indicate that thermochemical equilibrium calculations are applicable to gas and grain chemistry in the circumstellar shells of AGB stars. First, during the past forty years, thermochemical equilibrium (i.e., condensation) calculations have been used to predict the chemistry and mineralogy of dust grains in the solar nebula. The reviews by Larimer (1988), Lewis (1995), and Fegley (1997) show that these predictions generally agree well with the observed chemistry and mineralogy of chondritic meteorites and with the bulk compositions of planets and satellites. This agreement is significant because model pressures and temperatures in the solar nebula are similar to model pressures and temperatures in grain-forming regions of CS of cool stars.

Second, as discussed below and in more detail by Lodders \& Fegley (1997a), thermochemical equilibrium calculations of grain formation from an otherwise solar gas with a $\mathrm{C} / \mathrm{O}$ ratio $>1$ (i.e., around carbon stars) predict several features of circumstellar grain chemistry that are observed in presolar grains in meteorites. These features include the incorporation of TiC-bearing grains inside graphite grains, the formation of solid solutions of Mo- and $\mathrm{Zr}$ carbides with $\mathrm{TiC}$, and the trace element patterns observed in SiC grains.

Third, consideration of the characteristic time scales for chemical reactions $\left(t_{\text {chem }}\right)$ and of the characteristic time scales for expansion or cooling of gas in circumstellar shells $\left(\mathrm{t}_{\text {cool }}\right)$ indicate that circumstellar shells can be divided into three regions. In the inner regions where temperatures are high and grain formation occurs, $t_{\text {chem }}<t_{\text {cool }}$ and chemical equilibrium is reached. Conversely, in the outer regions where temperatures are low, $t_{\text {chem }}>t_{\text {cool }}$ and chemical equilibrium is not reached. In between these two regions is an intermediate zone where $t_{c h e m}=t_{c o o l}$ and chemical equilibrium is quenched. Finally, calculations of gas-grain chemical reaction rates using the simple collision theory of Fegley (1988) show that gas-grain chemistry proceeds very rapidly at high temperatures at which circumstellar grains such as $\mathrm{TiC}$, graphite, and $\mathrm{SiC}$ form.

\section{Major element condensates in circumstellar shells}

The gas and dust chemistry in red giant atmospheres depends on how much CNO- and triple alpha-processed material is dredged-up to the surface. An increase of $\mathrm{C}$ in an otherwise approximately solar composition gas increases the $\mathrm{C} / \mathrm{O}$ ratio and is responsible for the different chemistry seen in giants of type $\mathrm{M}$ $(\mathrm{C} / \mathrm{O}$ from solar to $<1$ ), type $\mathrm{S}(\mathrm{C} / \mathrm{O} \sim 1$ ) and type $\mathrm{N}$ (normal carbon stars, $\mathrm{C} / \mathrm{O}>1)$. The specific types of condensates depend on temperature $(\mathrm{T})$, pressure $(\mathrm{P})$, and bulk elemental composition and are predicted by thermochemical equilibrium calculations. Descriptions of the computational methods for these calculations are given by Larimer (1988) and Fegley \& Lodders (1994). In oxidizing environments $(\mathrm{C} / \mathrm{O} \sim$ solar $)$ refractory oxides and silicates form while under reducing conditions $(\mathrm{C} / \mathrm{O}>1)$, refractory carbides, nitrides and sulfides form. Table 1 gives a list of the condensates (in order of appearance) of the major rock-forming elements for each element. Interestingly, $\mathrm{Mg}$ and $\mathrm{Si}$ form silicates under oxidizing and reducing conditions, although the condensation 
Table 1. Major Element Condensates Expected in M- and C-stars *

\begin{tabular}{|c|c|c|c|c|c|}
\hline \multirow[t]{2}{*}{ Element } & \multirow[t]{2}{*}{ Abundance $^{8}$} & \multicolumn{2}{|c|}{ M-stars } & \multicolumn{2}{|r|}{ C-stars } \\
\hline & & Formula & Mineral Name & Formula & Mineral Name \\
\hline 0 & $2.09 \times 10^{7}$ & \multicolumn{2}{|c|}{ oxides and silicates } & & silicates \\
\hline $\mathrm{C}$ & $1.00 \times 10^{7}$ & - & - & $\begin{array}{l}\mathrm{TiC} \\
\mathrm{C} \\
\mathrm{SiC}\end{array}$ & $\begin{array}{l}\text { titanium carbide } M \\
\text { graphite } C S, M \\
\text { silicon carbide } C S, M\end{array}$ \\
\hline $\mathbf{N}$ & $2.63 \times 10^{6}$ & - & - & $\begin{array}{l}\text { TiN } \\
\text { AlN }\end{array}$ & $\begin{array}{l}\text { osbornite } \\
\text { aluminum nitride }\end{array}$ \\
\hline $\mathbf{M g}$ & $1.02 \times 10^{6}$ & $\begin{array}{l}\mathrm{MgAl}_{2} \mathrm{O}_{4} \\
\mathrm{Mg}_{2} \mathrm{SiO}_{4} \\
\mathrm{MgSiO}_{3}\end{array}$ & $\begin{array}{l}\text { spinel M } \\
\text { forsterite CS } \\
\text { enstatite CS }\end{array}$ & $\begin{array}{l}\mathrm{MgS} \\
\mathrm{MgAl}_{2} \mathrm{O}_{4} \\
\mathrm{Mg}_{2} \mathrm{SiO}_{4} \\
\mathrm{MgSiO}_{3}\end{array}$ & $\begin{array}{l}\text { niningerite CS } \\
\text { spinel M } \\
\text { forsterite CS } \\
\text { enstatite CS }\end{array}$ \\
\hline $\mathrm{Si}$ & $1.00 \times 10^{6}$ & $\begin{array}{l}\mathrm{Ca}_{2} \mathrm{Al}_{2} \mathrm{SiO}_{7} \\
\mathrm{Mg}_{2} \mathrm{SiO}_{4} \\
\mathrm{MgSiO}_{3}\end{array}$ & $\begin{array}{l}\text { gehlenite } \\
\text { forsterite CS } \\
\text { enstatite CS }\end{array}$ & $\begin{array}{l}\mathrm{SiC} \\
\mathrm{FeSi} \\
\mathrm{Mg}_{2} \mathrm{SiO}_{4} \\
\mathrm{MgSiO}_{3}\end{array}$ & $\begin{array}{l}\text { silicon carbide } \mathrm{CS}, \mathrm{M} \\
\text { iron silicide } \\
\text { forsterite } \mathrm{CS} \\
\text { enstatite CS }\end{array}$ \\
\hline $\mathrm{Fe}$ & $8.91 \times 10^{5}$ & $\begin{array}{l}\mathrm{Fe} \\
(\mathrm{Fe}, \mathrm{Ni})_{3} \mathrm{P} \\
\mathrm{FeS}\end{array}$ & $\begin{array}{l}\text { iron metal } \\
\text { schreibersite } \\
\text { troilite }\end{array}$ & $\begin{array}{l}\text { FeSi } \\
\mathrm{Fe} \\
\mathrm{FeS}\end{array}$ & $\begin{array}{l}\text { iron silicide } \\
\text { iron metal } \\
\text { troilite }\end{array}$ \\
\hline $\mathbf{S}$ & $4.47 \times 10^{5}$ & $\mathrm{FeS}$ & troilite & $\begin{array}{l}\mathrm{CaS} \\
\mathrm{MgS} \\
\mathrm{FeS}\end{array}$ & $\begin{array}{l}\text { oldhamite } \\
\text { niningerite CS } \\
\text { troilite }\end{array}$ \\
\hline Al & $8.51 \times 10^{4}$ & $\begin{array}{l}\mathrm{Al}_{2} \mathrm{O}_{3} \\
\mathrm{CaAl}_{12} \mathrm{O}_{19} \\
\mathrm{CaAl}_{4} \mathrm{O}_{7} \\
\mathrm{Ca}_{2} \mathrm{Al}_{2} \mathrm{SiO}_{7} \\
\mathrm{MgAl}_{2} \mathrm{O}_{4} \\
\mathrm{CaAl}_{2} \mathrm{Si}_{2} \mathrm{O}_{8}\end{array}$ & $\begin{array}{l}\text { corundum CS, M } \\
\text { hibonite } \\
\text { grossite } \\
\text { gehlenite } \\
\text { spinel M } \\
\text { anorthite }\end{array}$ & $\begin{array}{l}\mathrm{AlN} \\
\mathrm{Al}_{2} \mathrm{O}_{3} \\
\mathrm{MgAl}_{2} \mathrm{O}_{4} \\
\mathrm{CaAl}_{2} \mathrm{Si}_{2} \mathrm{O}_{8}\end{array}$ & $\begin{array}{l}\text { aluminum nitride } \\
\text { corundum CS, M } \\
\text { spinel } M \\
\text { anorthite }\end{array}$ \\
\hline $\mathrm{Ca}$ & $6.46 \times 10^{4}$ & $\begin{array}{l}\mathrm{CaTiO}_{3} \\
\mathrm{CaAl}_{12} \mathrm{O}_{19} \\
\mathrm{CaAl}_{4} \mathrm{O}_{7} \\
\mathrm{Ca}_{2} \mathrm{Al}_{2} \mathrm{SiO}_{7} \\
\mathrm{CaAl}_{2} \mathrm{Si}_{2} \mathrm{O}_{8}\end{array}$ & $\begin{array}{l}\text { perovskite } \\
\text { hibonite } \\
\text { grossite } \\
\text { gehlenite } \\
\text { anorthite }\end{array}$ & $\begin{array}{l}\mathrm{CaS} \\
\mathrm{CaAl} \\
\mathrm{Si}_{2} \mathrm{O}_{8}\end{array}$ & $\begin{array}{l}\text { oldhamite } \\
\text { anorthite }\end{array}$ \\
\hline $\mathrm{Na}$ & $5.75 \times 10^{4}$ & $\mathrm{NaAlSi}_{3} \mathrm{O}_{8}$ & albite & $\mathrm{NaAlSi}_{3} \mathrm{O}_{8}$ & albite \\
\hline $\mathrm{Ni}$ & $5.01 \times 10^{4}$ & $\begin{array}{l}\mathrm{FeNi} \\
(\mathrm{Fe}, \mathrm{Ni})_{3} \mathrm{P}\end{array}$ & $\begin{array}{l}\text { kamacite \& taenite } \\
\text { schreibersite }\end{array}$ & $\begin{array}{l}\mathrm{FeNi} \\
(\mathrm{Fe}, \mathrm{Ni})_{3} \mathrm{P}\end{array}$ & $\begin{array}{l}\text { kamacite \& taenite } \\
\text { schreibersite }\end{array}$ \\
\hline $\mathrm{Cr}$ & $1.35 \times 10^{4}$ & $\mathrm{Cr}$ in $\mathrm{FeNi}$ & alloy & $\mathrm{FeCr}_{2} \mathrm{~S}_{4}$ & daubréelite \\
\hline Mn & $9.33 \times 10^{3}$ & $\mathrm{Mn}_{2} \mathrm{SiO}_{4}$ & rhodonite in olivine & $(\mathrm{Mn}, \mathrm{Fe}) \mathrm{S}$ & alabandite \\
\hline $\mathbf{P}$ & $8.13 \times 10^{3}$ & $(\mathrm{Fe}, \mathrm{Ni})_{3} \mathrm{P}$ & schreibersite & $(\mathrm{Fe}, \mathrm{Ni})_{3} \mathrm{P}$ & schreibersite \\
\hline $\mathrm{Cl}$ & $5.25 \times 10^{3}$ & $\mathrm{Na}_{4}\left[\mathrm{AlSiO}_{4}\right]_{3} \mathrm{Cl}$ & sodalite & $\mathrm{NaCl}(?)$ & halite (?) \\
\hline $\mathbf{K}$ & $3.72 \times 10^{3}$ & $\mathrm{KAlSi}_{3} \mathrm{O}_{8}$ & orthoclase & $\mathrm{KAISi}_{3} \mathrm{O}_{8}$ & orthoclase \\
\hline $\mathrm{Ti}$ & $2.40 \times 10^{3}$ & $\mathrm{CaTiO}_{3}$ & perovskite & $\begin{array}{l}\text { TiC } \\
\text { TiN }\end{array}$ & $\begin{array}{l}\text { titanium carbide } \mathrm{M} \\
\text { osbornite }\end{array}$ \\
\hline
\end{tabular}

* condensates are listed in order of appearance for each element $\S$ solar abundances on a scale $\mathrm{Si}=1 \times 10^{6}$ atoms (Lodders \& Fegley, 1998) CS: dust observed in circumstellar shells of AGB stars.

$\mathrm{M}$ : circumstellar grains found in meteorites. 
temperatures and absolute amount of silicates formed will vary with different redox state. The condensation temperatures of major compounds as a function of pressure are shown in Figures $1 \& 2$ for a solar composition gas and for a gas relevant for $\mathrm{C}$ stars. Graphs showing the percentage distribution of an element between different gases and condensates as a function of temperature can also be calculated, and some examples are given in Figure 3 of Glassgold (1996).

Condensates observed by infrared spectroscopy of CS and by analytical studies of circumstellar dust in meteorites are identified by the abbreviations "CS" and "M" in Table 1. Many of the condensates observed around cool stars are found as presolar (i.e., circumstellar) grains in meteorites. For example, silicate (olivine, pyroxene; $9.7 \mu \mathrm{m}$ emission; Woolf \& Ney 1969) and corundum (13 $\mu \mathrm{m}$ emission, Onaka et al. 1989) dust is observed in CS of M giants and circumstellar corundum and spinel grains are found in acid-resistant residues from meteorites (see Zinner 1997). Silicon carbide (11.3 $\mu \mathrm{m}$ emission; Gilra 1971; Gilra \& Code 1971; Forrest et al. 1975), carbon (7.5 \& $23 \mu$ m emission; Omont 1991, Martin \& Rogers 1987), and MgS (30 $\mu \mathrm{m}$ emission; Goebel \& Moseley $1985)$ are observed in infrared spectra of $\mathrm{N}$ stars; and circumstellar graphite and $\mathrm{SiC}$ are found in meteorites. Titanium carbide (and other refractory carbide) inclusions in meteoritic circumstellar graphite indicates the condensation sequence $\mathrm{TiC}$, graphite, $\mathrm{SiC}$ around carbon stars.

Some of the condensates listed in Table 1 are not yet observed around cool stars. For example, $\mathrm{Fe}$ is about as abundant as $\mathrm{Si}$ and $\mathrm{Mg}$ and it is implausible that Fe-bearing condensates will not form. As shown in Table 1, equilibrium calculations predict that Fe alloy should form around $\mathrm{M}$ stars and some of it may react with $\mathrm{H}_{2} \mathrm{~S}$ gas to form $\mathrm{FeS}$ (troilite) at lower temperatures. In the more reducing environment of $\mathrm{N}$ stars, FeSi should form. If equilibrium persists down to very low temperatures $<500 \mathrm{~K}$, which may be unlikely (cf. Palme \& Fegley 1990), appreciable amounts of $\mathrm{Fe}$ can be incorporated into olivine as $\mathrm{Fe}_{2} \mathrm{SiO}_{4}$ and into pyroxene as $\mathrm{FeSiO}_{3}$. Thus the failure to observe Fe-bearing condensates such as Fe alloy, FeSi, and FeS must be due to other causes. Two possible causes are an absence of distinctive IR emission features at observable wavelengths or a lack of laboratory data on the IR spectra of predicted phases. Condensates such as $\mathrm{TiC}, \mathrm{CaS}$, and $\mathrm{AlN}$ have not yet been identified around carbon stars, but the abundances of these condensates are limited by the elemental abundances of $\mathrm{Ti}$, $\mathrm{Ca}$, and $\mathrm{Al}$, which are much lower than the elemental abundance of Si. Finally, some condensates have not yet been found as circumstellar grains in meteorites because they are sensitive to water $(\mathrm{CaS}, \mathrm{MgS}, \mathrm{AlN})$ and are also less resistant than $\mathrm{SiC}$ or graphite to the corrosive acids used to dissolve away the bulk of the meteorite. Sensitive in situ searches can be used to detect these condensates.

\section{Influence of total pressure and $\mathrm{C} / \mathrm{O}$ ratio}

Condensation temperatures generally decrease with decreasing total pressure. Fig. 1 shows the condensation temperatures for major element condensates as a function of total pressure for a solar composition gas appropriate for $M$ stars. Also shown are condensation temperatures for very refractory trace element oxides $\left(\mathrm{HfO}_{2}, \mathrm{ZrO}_{2}\right)$, which condense at even higher temperatures than corundum. The graph also indicates that the initial condensates can trans- 


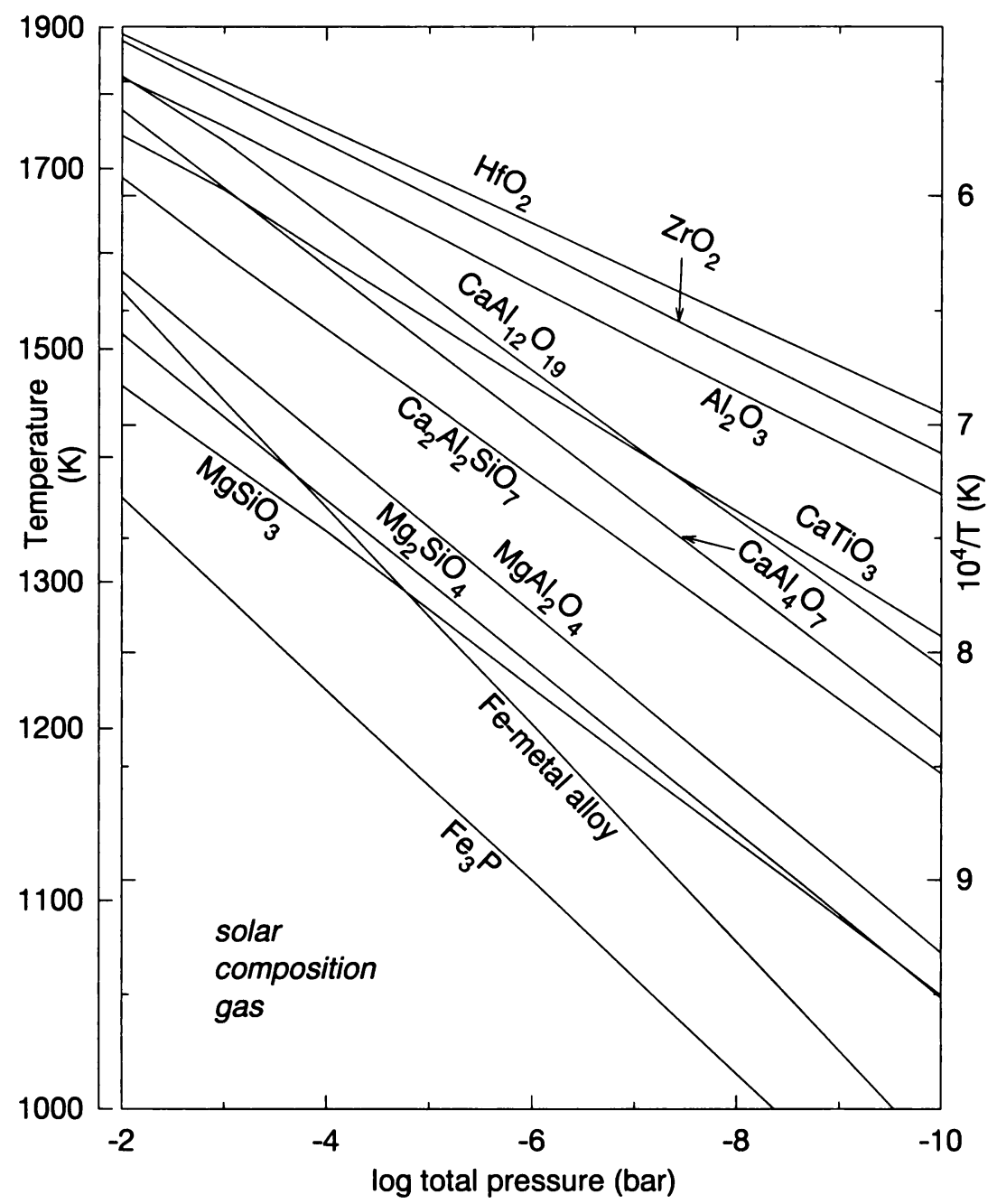

Figure 1. Major element condensation temperatures as a function of total pressure for a solar composition gas $(\mathrm{C} / \mathrm{O}=0.48)$. Note that the $\mathrm{y}$-axis is linear with $1 / \mathrm{T}$. 
form into other phases. For example, corundum reacts with $\mathrm{Ca}(\mathrm{g})$ to hibonite, which changes into grossite and eventually into gehlenite at lower temperatures. Gehlenite is the first Si-bearing condensate but because $\mathrm{Ca}$ and $\mathrm{Al}$ are much less abundant than $\mathrm{Si}$, the amount of total $\mathrm{Si}$ tied up in gehlenite is very small. Similarly, some corundum reacts with $\mathrm{Mg}(\mathrm{g})+\mathrm{H}_{2} \mathrm{O}(\mathrm{g})$ to form spinel but only a small amount of $\mathrm{Mg}$ is in spinel, because the spinel abundance is limited by the $\mathrm{Al}$ abundance. The major $\mathrm{Mg}$ - and $\mathrm{Si}$-bearing condensate is forsterite $\left(\mathrm{Mg}_{2} \mathrm{SiO}_{4}\right.$, the $\mathrm{Mg}$-endmember of the olivine $(\mathrm{Mg}, \mathrm{Fe}){ }_{2} \mathrm{SiO}_{4}$ solid solution). At lower temperatures, forsterite reacts with $\mathrm{SiO}(\mathrm{g})$ to form enstatite $\left(\mathrm{MgSiO}_{3}\right.$, the $\mathrm{Mg}$-endmember of the pyroxene $(\mathrm{Mg}, \mathrm{Fe}) \mathrm{SiO}_{3}$ solid-solution $)$.

In addition to the pressure sensitivity of condensation temperatures, the $\mathrm{C} / \mathrm{O}$ ratio influences the condensation temperatures (see detailed discussion by Lodders \& Fegley $1995,1997 \mathrm{a})$. An increase of the $\mathrm{C} / \mathrm{O}$ ratio from solar $(0.48)$ to unity causes a drop in oxide and silicate condensation temperatures because more oxygen is tied up in $\mathrm{CO}$ and less $\mathrm{H}_{2} \mathrm{O}$ is available for condensation reactions at higher temperatures. This effect becomes important in atmospheres of $\mathrm{S}$ stars, which have elevated $\mathrm{C} / \mathrm{O}$ ratios. Thus, we expect dust formation in $\mathrm{S}$ stars to occur at lower temperatures (i.e., farther out in the CS) than in M stars (assuming similar pressure-temperature conditions in atmospheres of $\mathrm{M}$ and $\mathrm{S}$ stars). As a consequence, dust-driven winds in $\mathrm{S}$ stars may become less effective in increasing mass-loss rates, which could explain the generally lower mass-loss rates in S stars than in M- or C stars (e.g., Bieging \& Latter 1994, Jura 1988).

Near a $\mathrm{C} / \mathrm{O}$ ratio of unity, the types of condensates change from oxides and silicates to carbides, sulfides, and nitrides (e.g., Larimer 1975, Larimer \& Bartholomay 1979, Lodders \& Fegley 1995, 1997a). Condensation temperatures for wide $\mathrm{P}-\mathrm{T}$ and $\mathrm{C} / \mathrm{O}$ ranges are listed by Lodders \& Fegley (1995). Fig. 2 shows condensation temperatures for major element condensates in a $\mathrm{N}$ star composition gas with $\mathrm{C} / \mathrm{O}=1.1$ (CNO abundances from Lambert et al. 1986, otherwise solar composition). In addition to the major elements, $\mathrm{ZrC}$, the most refractory trace element carbide, is also shown. As is the case for condensates under more oxidizing conditions, condensation temperatures drop with decreasing total pressure. The exception is graphite, whose condensation temperature is not very pressure sensitive. As a consequence, the condensation sequence of $\mathrm{TiC}$, graphite and $\mathrm{SiC}$ is very sensitive to the total pressure. At $\mathrm{P}>10^{-3.5}$ bar, the condensation sequence is $\mathrm{TiC}, \mathrm{SiC}, \mathrm{C}$; from $10^{-3.5}$ bar to $10^{-5.5}$ bar the sequence is $\mathrm{TiC}, \mathrm{C}, \mathrm{SiC}$; and at low pressures $\mathrm{P}<10^{-5.5}$ bar, the sequence is $\mathrm{C}, \mathrm{TiC}, \mathrm{SiC}$. These $\mathrm{P}$-dependent condensation sequences are only valid for $\mathrm{C} / \mathrm{O}=1.1$ because the condensation sequence depends on total pressure and $\mathrm{C} / \mathrm{O}$ ratio. Higher $\mathrm{C} / \mathrm{O}$ ratios at a given $\mathrm{P}$ increase the condensation temperature of carbon thus shifting the pressure range where the condensation sequence is $\mathrm{TiC}, \mathrm{C}, \mathrm{SiC}$ to higher pressure values.

The condensation sequence $\mathrm{TiC}, \mathrm{C}, \mathrm{SiC}$ is recorded in circumstellar graphite grains where $\mathrm{TiC}$ as well as $\mathrm{ZrC}-\mathrm{MoC}$ - $\mathrm{TiC}$ carbide alloys are often embedded in the center of graphite, indicating that these refractory carbides formed prior to graphite and served as nucleation seeds (see Bernatowicz et al. 1996 for details). 


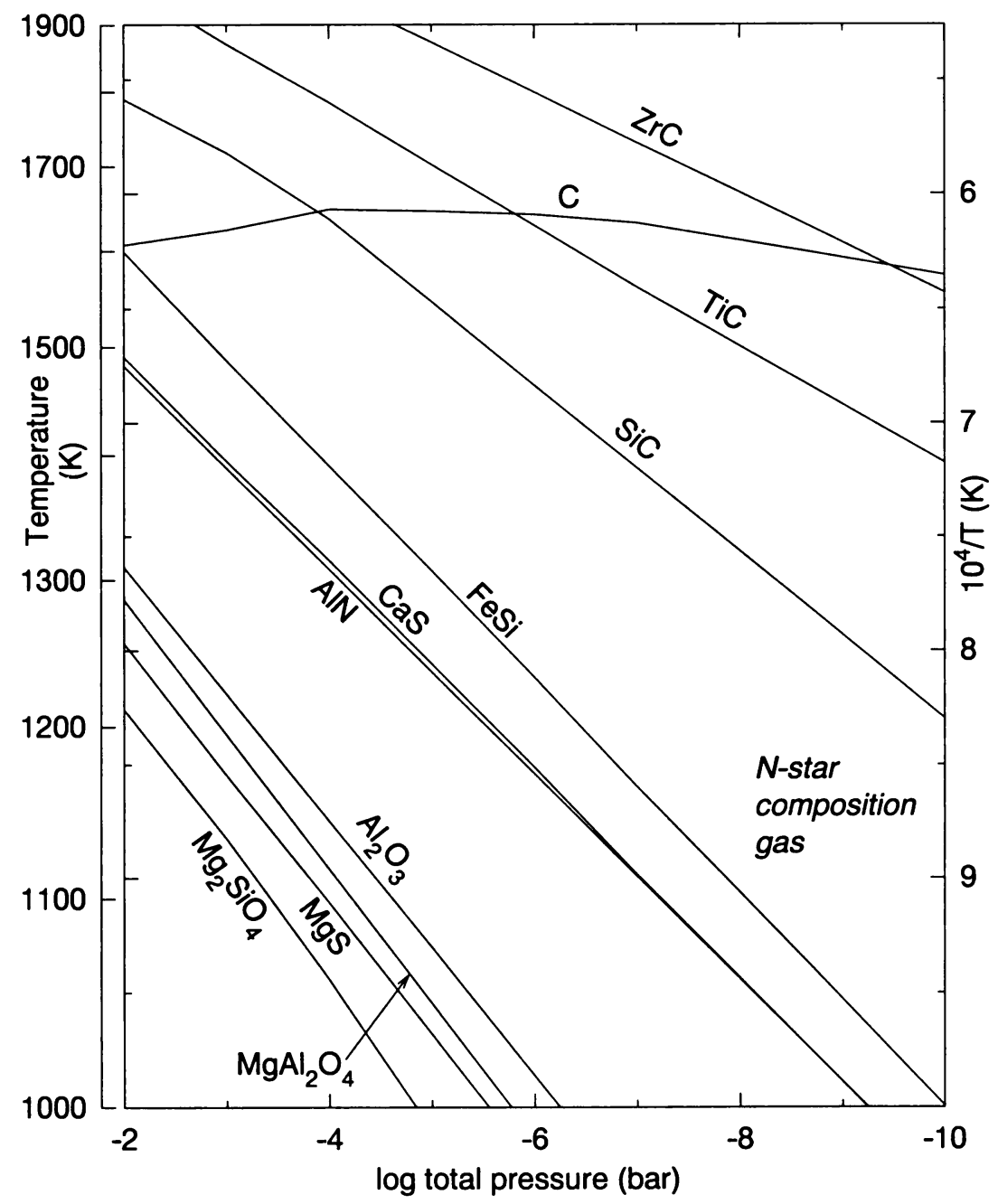

Figure 2. Major element condensation temperatures as a function of total pressure for a gas with average $\mathrm{N}$ star abundances of $\mathrm{C}, \mathrm{N}, \mathrm{O}$ $(\mathrm{C} / \mathrm{O}=1.1$; Lambert et al. 1986) and otherwise solar composition. 


\section{Influence of nitrogen abundance}

Another important influence on condensation temperatures is the nitrogen abundance. The relative nitrogen abundances increase from $\mathrm{M}$ - to $\mathrm{S}$ stars because of CNO-cycle processing and dredge-up; and enhancements of nitrogen may also be present in $\mathrm{C}$ stars. This could be the case for some $\mathrm{C}$ stars with enhanced HCN emissions (Jura 1991). Higher than solar abundances of $\mathrm{N}$ are known for $\mathrm{R}$ stars (Dominy 1984) and although Lambert et al. (1986) find approximately solar Nabundances, further analyses of $\mathrm{N}$ - and $\mathrm{J}$ carbon stars are needed to clarify the $\mathrm{N}$ abundances in these stars. An increase in $\mathrm{N}$ abundances does not influence condensation temperatures of oxides and silicates (e.g., M- and S stars) because $\mathrm{N}$ does not affect the gas chemistry relevant for oxide condensation. However, an increase in $\mathrm{N}$ abundances in $\mathrm{C}$ stars locks more carbon into $\mathrm{CN}(\mathrm{g})$ and $\mathrm{HCN}$ (g) which causes a decrease in condensation temperatures of C-bearing condensates. For example, an increase of the solar nitrogen abundance by a factor of 100 lowers graphite condensation temperatures by about $100-200 \mathrm{~K}$ and carbide condensation temperatures by $20-50 \mathrm{~K}$ (depending on total $\mathrm{P}$ and $\mathrm{C} / \mathrm{O}$ ratio). Such an increase in $\mathrm{N}$ abundance also causes an increase in nitride condensation temperatures (e.g., AlN condenses $50 \mathrm{~K}$ higher) but does not lead to formation of trace element nitrides instead of carbides as initial condensates.

\section{Mythical condensates}

There are also several compounds (e.g., pyrite, $\mathrm{FeS}_{2}$; w wistite, $\mathrm{FeO}$; hematite, $\mathrm{Fe}_{2} \mathrm{O}_{3}$; silica, $\mathrm{SiO}_{2}$; silicon disulfide, $\mathrm{SiS}_{2}$; calcium dicarbide, $\mathrm{CaC}_{2}$ ) often discussed as potential condensates in the literature but none of these compounds can form at equilibrium in CS. For example, formation of pyrite from Fe-metal proceeds via $\mathrm{Fe}$ (metal) $+\mathrm{H}_{2} \mathrm{~S}=\mathrm{FeS}+\mathrm{H}_{2}$ and $\mathrm{FeS}+\mathrm{H}_{2} \mathrm{~S}=\mathrm{FeS}_{2}+\mathrm{H}_{2}$, which implies that all $\mathrm{Fe}$ has to be converted to $\mathrm{FeS}$ first before sulfurization to $\mathrm{FeS}_{2}$ proceeds. This requires very large sulfur partial pressures which are inconsistent with the solar atomic $S / F e$ ratio of $\sim 0.5$. Similarly, the formation of $\mathrm{SiS}_{2}$ is unreasonable. Silicon, together with $\mathrm{Mg}$, forms more stable forsterite and enstatite instead of $\mathrm{SiS}_{2}$ and $\mathrm{SiO}_{2}$ (see Figures $1 \& 2$ ). Hematite formation requires a very oxidizing gas and proceeds via Fe (metal) to magnetite to hematite. However, low temperature oxidizing conditions in a solar composition gas are only sufficient to allow magnetite formation at low $\mathrm{T}$, so stars don't rust.

\section{Dust formation locations and nucleation}

As discussed in the previous paragraphs, modeling dust forming locations in CS depends on the atmospheric P-T conditions and bulk elemental abundances. Although both these parameters need refinement, using available $\mathrm{P}-\mathrm{T}$ models and abundances, dust formation locations predicted at thermochemical equilibrium (i.e., supersaturation ratios $S=1$ ) concur with astronomical observations that dust forms close to the star (3-10 stellar radii) in $\mathrm{M}$ as well as $\mathrm{N}$ stars (e.g., Anandarao et al. 1993; Bergeat et al. 1976; Danchi \& Bester 1995). This suggests that nucleation does not require high supersaturation ratios and proceeds relatively rapidly. In this respect it is also very important to consider stellar vari- 
ability. During minimum dust formation is enhanced and dust must nucleate and move outward from the CS before the variability cycle moves to maximum, where dust evaporation can occur. Such a scenario has support from the observations of the carbon Mira R For, of which the central star shows increased obscuration during minimum phase (Le Bertre 1988). Recently, variations of the silicate emission as a function of light curve have been reported for oxygen-rich long-period variables (Creech-Eakman et al. 1997).

This scenario can be tested by making observations of the $\mathrm{C} / \mathrm{O}$ ratio, $\mathrm{SiC}$ and $\mathrm{C}$ dust abundances and trace element abundances. For example, during minimum, formation of carbon and $\mathrm{SiC}$ dust removes carbon from the gas and the $\mathrm{C} / \mathrm{O}$ ratio in the gas decreases toward unity (Fix 1969; Lodders \& Fegley 1997a). As noted by Fix (1969), grains formed during minimum will evaporate again and raise the $\mathrm{C} / \mathrm{O}$ ratio back to the original value. However, if dust is removed from the $\mathrm{CS}$ by radiation pressure, the gas remains at a lower $\mathrm{C} / \mathrm{O}$ ratio. Gas fall-back onto the star during contraction then causes a "dilution" of the photospheric gas, which then is observed to have a lower $\mathrm{C} / \mathrm{O}$ ratio. This could be one reason why the $\mathrm{C} / \mathrm{O}$ ratios in $\mathrm{N}$ stars determined from the gas phase are close to unity (Lambert et al. 1986) while the hotter and dust-free $\mathrm{R}$ stars have higher $\mathrm{C} / \mathrm{O}$ ratios (Dominy 1984). If condensation and removal of carbonaceous dust takes place in $\mathrm{C}$ stars, the $\mathrm{C} / \mathrm{O}$ ratio determined from the gas cannot be representative of the bulk $\mathrm{C} / \mathrm{O}$ ratio, which then needs to be determined from $\left(\mathrm{C}_{\text {dust }}+\mathrm{C}_{\text {gas }}\right) / \mathrm{O}$. Nevertheless, the determination of the $\mathrm{C} / \mathrm{O}$ ratio as a function of variability may prove a sensitive test of dust formation.

Similarly, the trace element chemistry in circumstellar grains in meteorites and stellar atmospheres indicates that fractional condensation takes place in CS (see detailed discussion by Lodders \& Fegley 1997a, b). Fractional condensation into $\mathrm{SiC}$ depletes the gas in refractory elements such as $\mathrm{Ti}, \mathrm{Zr}, \mathrm{REE}$ (Rare Earth Elements), while the more volatile elements such as $\mathrm{Sr}$ and $\mathrm{Ba}$ require much lower temperatures to be scavenged into $\mathrm{SiC}$. The analyses of circumstellar $\mathrm{SiC}$ grains in meteorites revealed that many $\mathrm{SiC}$ grains are depleted in $\mathrm{Sr}$ and $\mathrm{Ba}$ implying that the $\mathrm{SiC}$ grains were removed from equilibrium with the gas at relatively high temperatures in the CS. This means that the grains formed relatively close to the star. The trace element abundances also indicate that grain removal from the CS must have taken place at different distances in the CS to explain the different types of trace element abundance patterns seen in the grains. As in the case above for carbon dust removal, we expect to see an effect in the remaining gas abundances in the stellar atmospheres. Since $\mathrm{Sr}$ and $\mathrm{Ba}$ are not removed into grains, the remaining gas becomes relatively enriched in $\mathrm{Sr}$ and $\mathrm{Ba}$. If grain formation and removal from the $\mathrm{CS}$ takes place preferentially during minimum, the gas enriched in $\mathrm{Sr}$ and $\mathrm{Ba}$ falls back onto the photosphere (and thus line-forming region) during maximum phase and relative enrichments of these elements should become visible. In other words, the trace element abundances in the $\mathrm{SiC}$ grains and the stellar atmosphere gas become complementary and should mirror each other. Such complementary abundances are observed, supporting the fractional equilibrium condensation model.

Thus, the variability cycle puts constraints on nucleation timescales. If nucleation timescales were longer than the time between minimum (enhanced condensation) and maximum (evaporation of dust), we would not expect much 
dust at all in CS. The observation of dust in CS and the existence of circumstellar grains in meteorites means that dust nucleation and expulsion to the ISM proceeds within timescales of half the variability periods (e.g., typically 100/2 to $500 / 2$ days for SR and Mira variables). An observational constraint on nucleation timescales may also come from optical and IR observations as a function of light curve. As noted by Creech-Eakman et al. (1997), there seems to be a quarter cycle phase lag between the IR and optical light curves for the oxygen Mira AU Cyg (period 435 days). This suggests that appreciable amounts of dust form within about 110 days. The nucleation timescales are also reflected by the correlation of variability period with mass-loss rate, which depends on the amount of dust present.

\section{Required observations and laboratory work}

Better and more detailed abundance determinations in giant atmospheres are needed. Observations require refinements of $\mathrm{C} / \mathrm{O}$ ratios, nitrogen abundances and determination of metallicity and s-process element abundances. Of particular interest are studies of abundances as a function of variability cycle. For example, the condensation calculations suggest that the $\mathrm{C} / \mathrm{O}$ ratio (determined in the gas) is lower at minimum because of condensation of carbon into dust. Similarly, SiC band strength may increase at minimum due to increasing $\mathrm{SiC}$ condensation. The trace elements are diagnostic of gas-solid fractionation processes and volatility related fractionation processes may lead to enhancements of the more volatile trace elements in the gas phase at minimum.

In addition to stellar observations, more analytical data on individual submicron circumstellar grains in meteorites are needed. Their trace element abundances can reveal much about the formation conditions in CS.

Condensation calculations predict many yet unidentified major element condensates in CS. In O-rich CS, we expect Ca-Al-bearing phases (hibonite, grossite, gehlenite), spinel, and metal-alloy. Not yet identified minerals expected to be present in C-rich CS are spinel, AlN, CaS, FeSi. The infrared spectra for many of these minerals are poorly known and need to be investigated to aid identification of these phases in stellar spectra. There are also predicted refractory trace element condensates which may be present in circumstellar grains, such as $\mathrm{HfO}_{2}$ and $\mathrm{ZrO}_{2}$ from $\mathrm{M}$ stars. Refractory carbides such as $\mathrm{HfC}, \mathrm{NbC}, \mathrm{TaC}$ are expected to be present in the $\mathrm{TiC}-\mathrm{ZrC}-\mathrm{MoC}$ alloys observed in circumstellar graphite grains. However, $\mathrm{Hf}, \mathrm{Nb}$, and $\mathrm{Ta}$ are much less abundant than $\mathrm{Zr}$ or Mo and cannot be detected until advanced instrumentation becomes available.

Acknowledgments. K. L. thanks the IAU Symposium organizing committee and the Université de Montpellier for the invitation to the enjoyable meeting and for travel support. Work supported by the NASA Origins Program (NAG5-4323).

\section{References}

Anandarao B.G., Pottasch S.R., Vaidya D.B., 1993, A\&A 273, 570

Bergeat J., Lefèvre J., Kandel R., Lunel M., Sibille F., 1976, A\&A 52, 245 
Bernatowicz T.J., Cowsik R., Gibbons P.C., et al., 1996, ApJ 472, 760

Bieging J.H., Latter W.B., 1994, ApJ 422, 765

Creech-Eakman M.J., Stencel R.E., Williams W.J., Klebe D.I., 1997, ApJ 477, 825

Danchi W.C., Bester M., 1995, Ap\&SS 224, 339

Dominy J.F., 1984, ApJS 55, 27

Fegley B., 1988, in Workshop on the Origins of Solar Systems, eds. J.A. Nuth and P. Sylvester, LPI Technical Report 88-04, Houston TX, Lunar and Planetary Institute, p. 51

Fegley B., 1997, in Encyclopedia of Planetary Sciences, eds. J.H. Shirley and R.W. Fairbridge, London, Chapman \& Hall, p. 169

Fegley B., Lodders K., 1994, Icarus 110, 117

Fix J.D., 1969, MNRAS 146, 37

Forrest W.J., Gillett F.C., Stein W.A., 1975, ApJ 195, 423

Gilra D.P., 1971, Nature 229, 237

Gilra D.P., Code A.D., 1971, BAAS 3, 379

Glassgold A.E., 1996, ARA\&A 34, 241

Goebel J.H., Moseley S.H., 1995, ApJ 290, L35

Jura M., 1988, ApJS 66, 33

Lambert D.L., Gustafsson B., Eriksson K., Hinkle K.H., 1986, ApJS 62, 373

Larimer J.W., 1975, Geochim. Cosmochim. Acta 39, 389

Larimer J.W., 1988, in Meteorites and the Early Solar System, eds. J.F. Kerridge and M.S. Matthews, Tucson AZ, Univ. of Arizona Press, p. 375

Larimer J.W., Bartholomay M., 1979, Geochim. Cosmochim. Acta 43, 1455

Le Bertre T., 1988, A\&A 190, 179

Lewis J.S., 1995, Physics and Chemistry of the Solar System, Academic Press, New York

Lodders K., Fegley B., 1995, Meteoritics 30, 661

Lodders K., Fegley B., 1997a, in Astrophysical Implications of the Laboratory Studies of Presolar Materials, eds. T. J. Bernatowicz and E. Zinner, Woodbury NY, Amer. Institute of Physics, AIP Conf. Proc. 402, p. 391

Lodders K., Fegley B., 1997b, ApJ 484, L71

Lodders K., Fegley B., 1998, The Planetary Scientist's Companion, New York, Oxford University Press

Martin P.G., Rogers C., 1987, ApJ 322, 374

Omont A., 1991, in Chemistry in space, eds. J. M. Greenberg and V. Pirronello, Kluwer Acad. Press, Dordrecht, p. 171

Onaka T., de Jong T., Willems F.J., 1989, A\&A 218, 169

Palme H., Fegley B., 1990, Earth Planet. Sci. Lett. 101, 180

Tsuji T., 1973, A\&A 23, 411

Woolf N.J., Ney E.P., 1969, ApJ 155, L181

Zinner E., 1997, in Astrophysical Implications of the Laboratory Studies of Presolar Materials, eds. T.J. Bernatowicz and E. Zinner, Woodbury NY, AIP Conf. Proc. 402, p. 3 


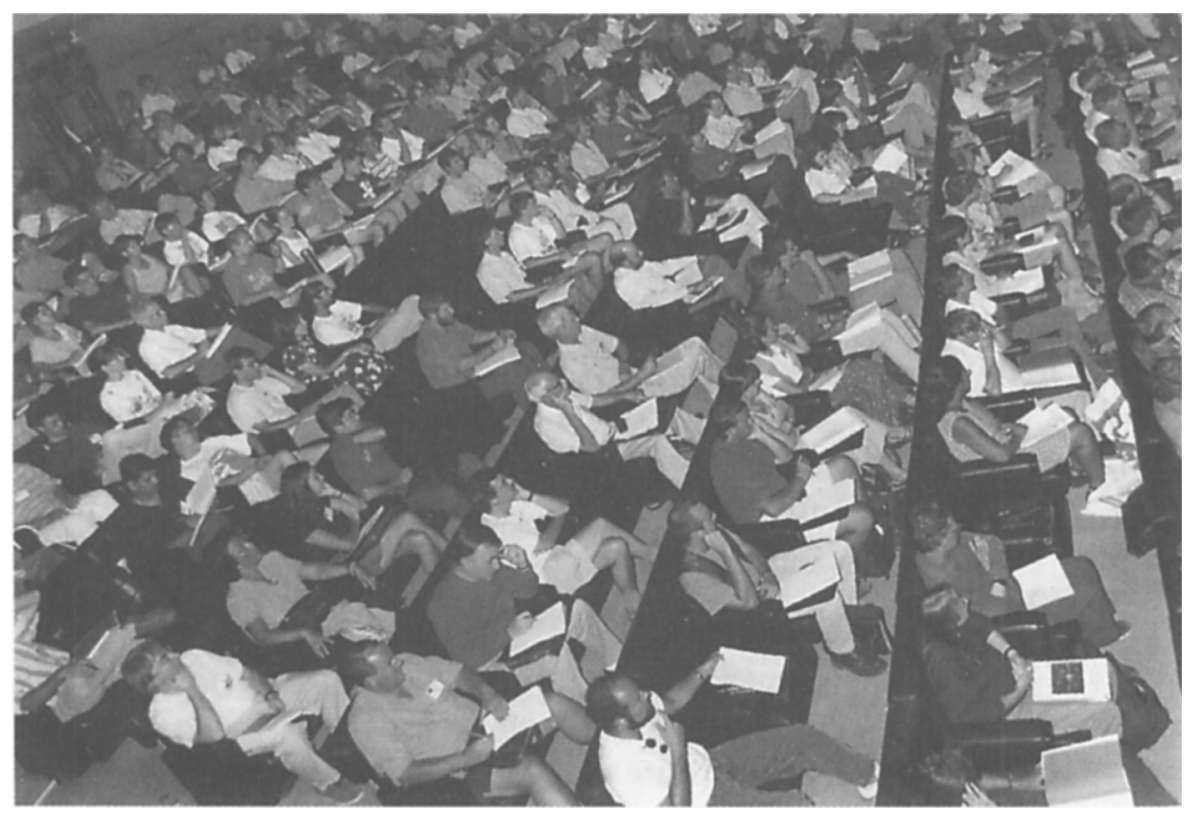

\section{The audience}

